\title{
Early Hepatocellular Carcinoma
}

National Cancer Institute

\section{Source}

National Cancer Institute. Early Hepatocellular Carcinoma. NCI Thesaurus. Code C96772.

A low grade, well-differentiated, early stage hepatocellular carcinoma. Grossly, it usually presents as a nodular lesion that measures less than $2 \mathrm{~cm}$ in diameter. 